\title{
En memoria de Lister
}

\author{
Walter Ledermann D.
}

\section{In homage to Lister}

Joseph Lister, who disputes with Klebs the third place as the Father of Microbiology, was just about to remain without a bacteria immortalizing his name. Thanks to Seeliger, now Listeria is used for identifying the genus that Pirie had already named Listerella in 1927. Through a quick review of the history of Listeria monocytogenes, we get to know the principal facts in the lives of Pirie and Seeliger, investigators with absolutely different characters. We also review a brief history of the life of the great researcher Lister, whose profound human qualities are described.

Key words: Listeria, Lister, Pirie, Seeliger.

Palabras clave: Listeria, Lister, Pirie, Seeliger.

\section{Hospital Luis Calvo Mackenna Santiago, Chile}

Laboratorio de Microbiología

Recibido: 18 agosto 2008

Aceptado: 25 agosto 2008

\section{Correspondencia a:}

Walter Ledermann Dehnhardt oncemayor11@gmail.com
$\mathrm{C}$ uando se habla de los padres de la microbiología se vienen a la mente los nombres de Koch y de Pasteur, siendo vanos los intentos por asociarles un tercero. El célebre historiador español Laín Entralgo menciona como candidato a T. A. Edwin Klebs, por sus deslumbrantes teorías sobre la enfermedad infecciosa, afirmando que "no muy inferiores a los de Pasteur y Koch son los de E. Klebs, tercero de los grandes fundadores de la microbiología médica"1, pero la mayoría de los microbiólogos, en charlas informales, suelen inclinarse por el inglés Joseph Lister, considerándolo a su vez como el padre de la antisepsia. Curiosamente, tal como le ocurriera a Pasteur, quien tuvo como premio de consuelo el género Pasteurella inmortalizando su nombre, Lister estuvo a punto de quedarse sin "su" bacteria, pero un investigador escocés, queriendo honrar seguramente a quien había sido un gran maestro de la cirugía en Glasgow, vino a corregir el olvido con la Listeria monocytogenes.

-Peor es mascar la hucha- habría dicho Lister, si hubiese sido filósofo u hombre con sentido del humor. Como buen sabio, estudioso y documentado, no ignoraría que la expresión "mascar lauchas" es sólo una deformación de la anterior. Su comentario, en todo caso, habría aludido a la insignificancia de la bacteria que le asignaron. Porque, aunque cause brotes letales y nuestra revista le dedique un número especial, Listeria monocytogenes es, para los bacteriólogos, una bacteria "menor", curiosa, escasa y rara.

Para empezar, es una bacteria zoonótica, productora en varios roedores un extraño trastorno caracterizado por fiebre y monocitosis, que no despertaba interés alguno entre los investigadores, hasta que en 1926 este enfermedad empezó a diezmar los conejos del laboratorio de la Universidad de Cambridge. Amenazadas tanto sus investigaciones como el presupuesto de su laboratorio, tres microbiólogos -Murray, Webb y Swann- unieron sus esfuerzos, analizaron los animales enfermos, cultivaron su sangre y otros órganos e identificaron una nueva especie bacteriana, un bacilillo Gram positivo no esporulado que bautizaron como Bacterium monocytogenes ${ }^{2}$. Por sus caracteres se intentó asimilarlo sucesivamente a los géneros Corynebacterium y Erysipelothrix, y junto a ellos apareció desde entonces en todos los textos de microbiología, hasta que los estudios genéticos demostraron su pertenencia a un linaje algo lejano, de manera que hoy

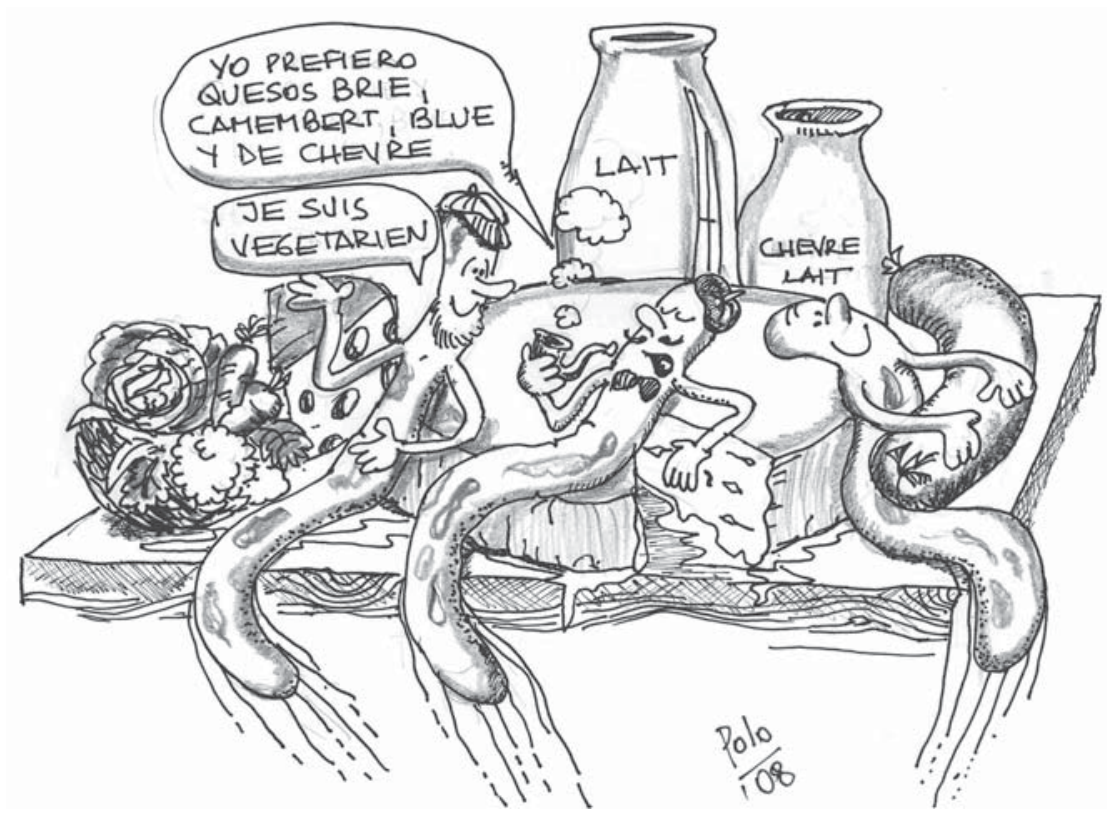


está en una familia aparte de la Subdivisión Clostridium: la familia Listeria-Brochothrix, equidistante y al medio de Bacillus y de Enterococcus. Pero nos estamos adelantando; hagamos una pausa y volvamos a nuestra historia.

Un año después del descubrimiento señalado, en 1927, Pirie descubrió también su bacilillo y lo llamó Listerella hepatolytica; sucesivos estudios y cambios de nombres llevarían a descubrir una identidad única para los diferentes bacilos encontrados, pasando por Bacterium monocytogenes hominis de Nyfeldt (1932), Corynebacterium parvulum de Schultz (1934), Erysipelothrix monocytogenes de Miles y Wilson (1946), Corynebacterium infantisepticum de Potel (1950), para terminar en 1957 como Listeria monocytogenes por gracia de Seeliger.

James Hunter Harvey Pirie, cuyo segundo nombre le venía como anillo al dedo, pues sería aventurero y cazador de bacterias, nació en 1877 , fue un niño muy despierto, estudió en la antigua Universidad de Edimburgo y se graduó en 1902. Seguramente conocía al famoso William Speirs Bruce (1867-1921), escocés como él, aunque nacido en Londres, quien estaba organizando una expedición antártica. Este Bruce descendía de una conspicua familia de arriesgados escoceses, cuyo tronco se remontaba al legendario Bruce que desafió al rey "Zanquilargo" de Inglaterra, continuando la rebelión de Wallace, y a la cual perteneciera también el descubridor de la Brucella melitensis ${ }^{3}$.

Había entre Bruce y Pirie muchos puntos de contacto y simpatía: su afición por las aventuras, por la exploración de regiones inhóspitas, por las ciencias naturales y por la medicina. En efecto, Bruce en un principio había intentado estudiar esta profesión, pero luego cambió de objetivo, deslumbrado por las ciencias naturales, desarrollando un vasto interés por una enormidad de disciplinas, para terminar abandonando sus estudios médicos y embarcándose como "asistente científico" en la Exploración Ballenera Dundee a la Antártica en 1892. Después de participar en varios viajes al Ártico, en las cuales fue formándose como oceanógrafo, postuló a un puesto científico en una gran expedición británica a la Antártica, la famosa Discovery Expedition, pero terminó peleando con Sir Clements Markham, presidente de la Royal Geographic Society, quien rechazara su proposición de incluir un segundo barco, y tomó la arriesgada decisión de hacer su propia Expedición Nacional, pero de Escocia y no Británica, que logró llevar a cabo entre 1902 y $1904^{4}$. Fue en esta ocasión cuando enroló a Pirie; bien podemos imaginar que ambos aventureros se conocían y que una tarde, departiendo en pub, diría Bruce:

- ¿Tienes pensado algo para los próximos dos años, James? Porque el viernes salimos hacia el Polo Sur...
Si fue así, Pirie aceptó y postuló a una plaza de "bacteriólogo y geólogo". En aquellos tiempos no existían ni mucha especialización ni muchas exigencias, y así se explica que un joven sin experiencia pudiera asumir este doble título sin rubor ni dificultad. Quizás no había muchos voluntarios que quisieran exponerse a las inclemencias del clima invernando en la isla Laurie, en el mar hoy llamado de Escocia, de manera que no es aventurado suponer que Bruce alentara la postulación de Pirie sin cuestionar sus títulos y lo enrolara gustoso, reproduciendo quizás un poco la relación que existiera entre Darwin y Fitz-Roy en el HMS Beagle: la marina de Su Majestad tiene muchos ejemplos de colaboración con la ciencia.

Recién se iniciaban las expediciones a la Antártica, procurando los distintos países establecer soberanías, de modo que las condiciones de los campamentos distaban mucho de las comodidades actuales. Allí James Pirie, enfrentado a condiciones bien rigurosas, endureció tanto su piel como su temple para futuras aventuras. Participó primero en la construcción de una estación metereológica y luego, ya adaptado al clima, llegó al mar de Weddell, iniciando investigaciones que darían origen a una serie de publicaciones posteriores, tanto en el campo de la bacteriología como de la geología, siendo estas últimas las más importantes, en especial las dedicadas a la glaciología de las islas Gough y Orkney. Como entretención adicional, o quizás para ponerse a tono con la "onda Darwin" que campeaba en el Reino Unido, desarrolló algunos estudios zoológicos. Y pudo agregar "también hago mapas", imitando la modestia de Leonardo, al poner a la cola del currículo que enviara al Rey de Francia la célebre frasecita "y también pinto".

Aventurero por naturaleza, Pirie se unió en 1913 a los Servicios Médicos Coloniales en Kenya, en una estadía muy breve, pues se desencadenó la Primera Guerra Mundial y de inmediato renunció para ingresar al ejército británico, como buen súbdito de Su Majestad. Se comportó con valor, sobrevivió en las trincheras, tanto a las balas como a las bacterias, y en 1918 aceptó el puesto de Superintendente de la División Rutinaria (iqué nombrecito más desanimante!) del Instituto de Investigación Médica en Johannesburgo. Ya nunca dejaría Sudáfrica, falleciendo allí en 1965, tras una dilatada carrera científica, de la cual la perla fue el descubrimiento de la Listeria monocytogenes ${ }^{5}$.

Pirie aisló su bacteria de un curioso roedor llamado gerbil, palabra inglesa para la cual no existe una adecuada traducción. Es como un ratoncillo, con largas y robustas extremidades posteriores, que le permiten desplazarse a grandes saltos, guardando el equilibrio con una cola más larga aún. Este Meriones unguiculatus vive en regiones desérticas de Asia y Africa, 
alimentándose de semillas y de pastos, y es capaz de sobrevivir en condiciones extremas de desecación con unas pocas gotas de agua al día.

El gerbil ha desarrollado un gran mimetismo con la arena, gracias al color de su piel, y tiene un oído finísimo, que le permite huir al primer ruidito sospechoso dando largos saltos, para esconderse en los túneles que ha excavado como madriguera, escena que habrán visto alguna vez los abonados al TV cable que ven el National Geographic: están los animalitos parados en dos patitas, mirando al vacío, como huasos en la estación de ferrocarril, listos para desaparecer en sus covachas al menor ruido, en una estampida silenciosa. Algunas especies se han hecho populares como mascotas, porque no son hediondos ni muerden ni rasguñan, a diferencia de los traidores hamster, siendo muy activos y curiosos, para deleite de los niños, si bien cuando están en cautiverio duermen la mayor parte del día ${ }^{6}$.

Al igual que sus colegas de Cambridge, nuestro héroe estaba estudiando la monocitosis de estos roedores autóctonos, logrando aislar del hígado de uno de los una bacteria que llamó Listerella hepatolytica, pues le dio más importancia al daño hepático que a la monocitosis periférica. Pirie hizo su publicación en 1927, en una inaccesible revista local $^{7}$ y sin conocer el trabajo de Murray, pues en aquel tiempo la divulgación de los artículos científicos se hacía por suscripciones a las revistas, que viajaban a través del correo regular, y Africa estaba lejos de Inglaterra.

Con su descripción de la bacteria como Bacterium monocytogenes hominis en 1932, Nyfeldt borró el nombre de Lister : habría de pasar un cuarto de siglo antes que Seeliger hiciera justicia al genial escocés y rebautizara al género como Listeria, dentro del cual se reconocen hoy seis especies, siendo Listeria monocytogenes la especie-tipo y la más frecuente y la más malvada.

Muchos médicos se sorprenden al saber que Lister nada tuvo que ver con el género microbiano que lleva su nombre: de hecho, cuando Murray descubrió la bacteria, Lister llevaba catorce años en su tumba. Si bien era cirujano, como muchos próceres de la microbiología, Lister no trabajó tanto en la identificación y cultivo de las bacterias como en la prevención de las infecciones nosocomiales. Es muy conocida su historia de cómo se interesó por evitar las infecciones de las heridas operatorias, que primero supuso contaminadas "por algún tipo de polen en el polvo en suspensión", para luego abrir los ojos a la verdad en 1865 con un trabajo de Pasteur sobre el origen de la putrefacción, comenzando a usar como antiséptico el ácido carbólico y luego el fénico, que utilizó primero en spray y luego en sofisticados equipos de pulveriza- ción de su propio diseño ${ }^{8}$, de los cuales se burlaban por igual alemanes y norteamericanos. Pues bien, de esa historia no diremos nada en esta ocasión, pues nos motiva más ir "a la esencia del hombre mismo".

Joseph Lister nació el 5 de abril de 1827 en el seno de una acomoda familia cuáquera de Upton, cerca de Londres. No era escocés, como se dice a veces, sino inglés, pero su nombre se liga a Escocia por haberse desempeñado muchos años en la Universidad de Glasgow, lo cual conspiraba contra su éxito, pues los científicos británicos estimaban que Glasgow era algo así como una aldea rural, de modo que no dieron crédito al sabio hasta que se trasladó a la capital del Reino Unido. Podríamos recurrir a un lugar común y decir que el amor por la ciencia lo traía en los genes ("lo tengo en el ADN", suelen decir hoy hasta los futbolistas, explicando alguna habilidad con el balón), porque su padre fue Joseph Jackson Lister, quien fuera uno de los pioneros en microscopía, inventando los lentes acromáticos.

Hombre de muchas inquietudes, como todos los verdaderos sabios, Lister decidió estudiar arte y lo hizo, graduándose con rapidez y facilidad, pero luego el microscopio comenzó a pesar en su ánimo y entró a estudiar medicina en 1848, graduándose con honores en 1852. ¡Qué corta era la carrera entonces!. Parece que el aforismo de Hipócrates "el arte es largo y la vida corta" no impresionaba a los ingleses. En 1856 entró como asistente al Royal Edimburg Infirmary como ayudante del cirujano James Syme, en cuya hija estaba interesado y con quien se casaría más tarde, siguiendo el ejemplo de muchos investigadores que facilitaron su carrera casándose con la hija del profesor ${ }^{9}$.

En este caso existió verdadero amor, pues Agnes era "poco agraciada"; sin embargo, era seria y formalita, compartiendo los ideales de vida de su pretendiente, quien jamás hubiera obrado por cálculo: "si tenía algún vicio, éste era un exceso de virtud", al decir de un biógrafo. Dicha Agnes, que tenía los ojos negros, expresión reservada y se peinaba con raya al medio, fue una abnegada ayudante para el genio, siempre dispuesta a motivarse por los intereses de su marido.

Siendo muy tímido y con un ligero tartamudeo, Lister tampoco era capaz de franquear estos obstáculos al expresarse por escrito y reescribía sus conferencias varias veces. Cada vez que tenía que hacer un discurso, se quedaba toda la noche anterior dictando a Agnes, quien tenía que hacer la doble función de amanuense y de crítico literario. Lister no llevaba apuntes a sus conferencias, sino el texto in extenso, para no verse obligado a improvisar, hecho que hubiera favorecido su tartamudeo; pese a la ayuda de su mujer, nunca terminaba su discurso a tiempo y lo iba corrigiendo todavía en el coche, de manera que solía llegar 
atrasado por darle los últimos toques. Su padre solía escribirle instándole a superar este defecto, pero era inútil ${ }^{10}$.

Lister fue siempre un cirujano y sólo a ratos un microbiólogo, por mucho que le fascinara el microscopio. Se explica así que uno de sus grandes aportes a la cirugía fuera la introducción de la sutura con catgut. Fabricado con la serosa del intestino gatuno y luego de cordero, era mayormente proteico y digerible; convencido de su utilidad, pues ya había diez años de experimentación previa, Lister lo perfeccionó, logrando esterilizarlo con cera fundida y fenolada. En 1869 cuando estaba pasando la Nochebuena en su vieja casa de Essex, requirió la ayuda de su sobrino Richman Godlee y aplicó cloroformo a una vaca, en la cual hizo una ligadura con catgut; un mes después, cuando el animal fue al matadero, un diestro matarife le envió el órgano donde se había hecho la sutura, que estaba enteramente reabsorbida ${ }^{10}$. Asegurado el éxito, se atrevió poco después a inaugurar su uso clínico con una mastectomía a su propia hermana.

Pocos saben que nuestro héroe, en uno de sus arrebatos microbiológicos y abandonando por un momento su labor quirúrgica, participó en la historia de la vacuna anti-neumocóccica, realizando vacunaciones en Sudáfrica. Motivado por su propia clasificación serológica del neumococo, hizo un preparado polivalente de los serotipos más conspicuos y, tras los ajustes cuantitativos preliminares, las emprendió contra los mineros nativos con tres dosis subcutáneas de siete mil millones de bacterias muertas, a razón de una inyección por semana. Con esta acción logró una caída drástica en la incidencia y en la mortalidad, siendo lo más importante que la vacuna protegió contra infecciones por los serotipos incluidos ${ }^{11}$, lo cual convierte a Lister en todo un precursor de las actuales penta, hepta y plurivalentes que se disputan el mercado.

Lister fue siempre un hombre de fe. Lo decimos no porque fuera un activo miembro de la Iglesia Episcopal Escocesa, sino por sus hechos y su forma de vida. Cuando veía a sus rivales hacer burla de sus pulverizaciones y rechazar sus aportes a la antisepsia, se refugiaba en la idea que su sostén estaba en un propósito divino, que era Dios quien había dictado este fin para su vida y, en tal sentido, actuaba como un cruzado. Si tuvo grandes oportunidades para hacer dinero con sus inventos y descubrimientos, no las aprovechó, mostrando siempre un supremo desinterés por su propio beneficio, al cual anteponía siempre el de sus pacientes, aduciendo que el talento se le había otorgado para servir a la humanidad.

Además de ser profundamente religioso, Lister era muy tímido y formalito, de manera que fue toda una irreverencia de nuestra parte suponerle el comentario filosófico acerca de mascar la hucha al principio de este artículo : lo más probable es que, importándole un pito la perpetuación de su nombre en la historia de la medicina, hubiera aceptado humildemente el designio divino de quedar ignorado. Sentíase dirigido por Dios para cumplir una función de utilidad pública, y le tenían sin cuidado la fama y el éxito puramente social y económico que sus investigaciones le pudieran reportar. Se entiende así que derivara hacia la prevención, como lo muestra su irrupción en el campo de las vacunas, y fundara un Instituto de Medicina Preventiva en 1891, siendo también un pionero en este campo.

En cuanto a su acción en el terreno curativo de las enfermedades infecciosas, existe una increíble historia atribuyéndole el descubrimiento de la penicilina en pleno siglo XIX, muchísimo antes de Fleming. Mac Farlane publicó en Cambridge en 1984 un libro sobre Alexander Fleming -The man and the myth $-^{12}$ donde se relata cómo cierta señora Ellen Jones, herida a raíz de un ataque aéreo alemán a Londres en 1940, contó al médico de turno que en su juventud, hacia 1884, el profesor Lister la habría sanado de un absceso usando penicilina. Muy sorprendido, el médico fue a investigar los registros del King's College Hospital, donde constaba la admisión de Miss Ellen Jones el 2 de noviembre de 1884, con un absceso glúteo derivado de un accidente de tránsito provocado por un coche de caballos.

La penicilina no aparecía en esos registros, sino en un cuadernillo en que la dama escribía pequeñas notas para llenar las horas vacías mientras permanecía hospitalizada. Aunque la tinta estaba algo desvaída con el paso de los años, la letra de la señora Jones era perfectamente reconocible en una página donde había escrito la letra de una canción muy popular en 1884 , que escuchaba tararear a los estudiantes, y en otra donde anotara el nombre del medicamento administrado por Lister.

Da la impresión que la enferma hubiera sido ayudada a trazar las últimas letras, pero se lee claramente la palabra "penicillim", con "eme" final. La evidencia es frágil y discutible, pero sería una bella historia si fuese verídica. No es improbable, pues en esa edad de oro de la naciente bacteriología muchos investigadores ensayaron, plenos de ilusión, terapias de antagonismo microbiano. Por otra parte, con su modestia característica, puede que el padre de la antisepsia no haya dado ninguna importancia a su descubrimiento.

Antes de pasar a Seeliger, el hombre más importante en la historia de la Listeria y quien decidiera inmortalizar en ella a Lister, revisaremos sucintamente los hechos que durante el siglo XX llevaron a establecerla como patógena. Varias observaciones llevaron al convencimiento de su participación en una enfermedad 
que afectaba al binomio madre-hijo: la madre se infectaba durante el embarazo, con un breve cuadro febril, algo así como un flu-like: aquéllo era lo visible, pero lo invisible era la bacteriemia, que iba a afectar a la placenta y pasar al feto, con múltiples focos, constituyendo así la entidad que los viejos maestros llamaban granulomatosis infantisepticum. Luego, a medida que se la descubría en tierra y en agua, así como en diversos animales afectados -peces, aves y mamíferos- y contaminando varios alimentos, se concluyó que su puerta de entrada era intestinal, afectando desde allí a dos grupos de edades: los muy niños y los muy ancianos.

Sin embargo, el camino no fue tan rápido como parece. Burn fue el primero en describir la listeriosis neonatal ${ }^{13}$ y más de veinte años después Benirschke comenzó a aclarar las rutas de transmisión de la madre hacia el feto y el recién nacido ${ }^{14}$. Hacia 1960 Delta propuso a Listeria como causa de meningitis del recién nacido ${ }^{15}$, iniciándose una década de intensos estudios sobre la constitución de la bacteria, su característica movilidad y su serología, así como el desarrollo de técnicas diagnósticas, incluyendo microscopia de inmuno fluorescencia. No hubo éxito ni mucho interés tampoco en desarrollar vacunas, quizás porque la ampicilina resultó ser un antibiótico activo y barato. En cuanto al problema gineco-obstétrico que representa, se han preferido las medidas de vigilancia y control del embarazo, ya que la conducta de esta bacteria se asemeja a la de Streptococcus agalactiae, contra la cual esta estrategia ha resultado efectiva.

Heinz Seeliger (1920-1997), el hombre que hizo justicia a Lister, merece toda nuestra atención por sus excepcionales cualidades humanas y se nos presenta como el último vástago del gran tronco de la bacteriología alemana de la época de Koch : no habría desentonado entre von Bhering, von Pettenkofer, Klebs, Loeffler, Eberth, Gaffky los otros. Bacteriólogo, serólogo y muchas cosas más, trabajó en el CDC de Atlanta y en el Seruminstitut de Copenhague, donde trabajaría con el sabio Kauffmann, el mismo de la clasificación serológica de las Salmonella, llegando más tarde a ser director del Centro Nacional para Referencia en Salmonella, en Bonn. También se interesó por los hongos : su tesis para profesor versó sobre la serología de las infecciones fúngicas y fue años después vicepresidente de la Sociedad Internacional de Micología Humana y Animal ${ }^{16}$.

Seeliger era un apasionado por la filogenia y la taxonomía, deslumbrado por el maravilloso espectáculo de la biodiversidad microbiana, llegando a ser coautor del Código Internacional de Nomenclatura Bacteriana. Pero la bacteria de su vida fue la Listeria monocytogenes, cuya serología precisó en 1969. En 1940 Paterson había iniciado la clasificación serológica es- tableciendo su estructura antigénica ${ }^{17}$, en tanto que Robbins y Griffin habían analizado las respuestas a determinados mosaicos antigénicos, pero faltaba que Seeliger diera al asunto el toque final: metódico, fino, incansable y tenaz, estudió miles de cepas, analizando los antígenos somáticos y flagelares, para delimitar 17 serotipos, predominando históricamente en clínica humana los $1 \mathrm{a}, 1 \mathrm{~b}$ y 4 b. También clasificó con certeza las especies del género, una de las cuales lleva hoy su nombre como Listeria seeligeri, y ahondó en la patogenia de la listeriosis tanto humana como animal, todo lo cual condensó en un texto clásico sobre esta bacteria.

Seeliger llegó a formar la colección más grande de cepas de Listeria que haya jamás existido. Se entiende entonces que, con tales disposiciones, paciencia y curiosidad, fuera coleccionista también de otras cosas y en sus ratos libres formó una bellísima y célebre colección de sellos postales con la historia de la microbiología. Y, last but not least, era historiador médico y creó un Archivo histórico para la Unión Internacional de Sociedades de Microbiología, entidad de la cual fue presidente entre 1978.

Según su hijo Michael, Heinz Seeliger tenía una memoria sorprendente y era capaz de recordar dónde y cuándo había encontrado cada sello de su colección, y lo mismo ocurría con sus cepas de Listeria, tanto así que un colega sostuvo que "la ciencia hubiera debido guardar su cerebro". Esa memoria nunca le permitió olvidar el día de 1938 en que los nazis lo sacaron del colegio a los 18 años, para enrolarlo en las fuerzas armadas y luchar por una causa insensata que no compartía, terminando prisionero de los rusos por varios años y sobreviviendo a esa prisión por milagro.

Hombre brillante, de múltiples inquietudes, amaba la música, tanto clásica como la ópera y el jazz, y le gustaba la danza y el patinaje artístico, aunque no los practicara $^{18}$.

Heinz Seeliger falleció en 1997, después de haber recibido numerosos y merecidos honores, entre los que destacan los máximos que conceden en microbiología las dos naciones que encabezaron la "guerra de los descubrimientos" a fines del siglo XIX: Alemania le concedió la Medalla Ferdinand Cohn y Francia la Medalla Pasteur en plata ${ }^{16}$.

Resulta irresistible la idea de hacer un contraste entre este coleccionista serio y metódico y el arriesgado Pirie, hombre de acción y de los grandes espacios abiertos. El escocés, nacionalista hasta el tuétano, quiso honrar a quien creía su compatriota o quizás a su profesor en Glasgow, pues bien pudo en algún momento ser su alumno; el alemán sólo pensó en hacer justicia volviendo sobre la idea de Pirie, borrada en el tiempo por investigadores de menor categoría. Como quiera que fuese, Lister tuvo su bacteria. 
- Si ésa es la voluntad de Dios... -murmuraría Lister, de haber estado vivo, al conocer el honor que le concedía Seeliger, descendiente de los alemanes que lo combatieron en su tiempo, y que vendría a sumarse a las muchas distinciones recibidas en vida- Pero, en verdad, no tenía para qué molestarse, Herr Heinz...

Y tendría razón: su grandeza no necesitaba de una bacteria para ser recordada.

\section{Resumen}

Joseph Lister, quien disputa con Klebs el tercer lugar como Padre de la Microbiología, estuvo a punto de quedarse sin una bacteria que inmortalizara su nombre. Gracias a Seeliger hoy se denomina Listeria al género que ya Pirie había propuesto como Listerella en 1927. En una rápida revisión de la historia de Listeria monocytogenes conocemos los hechos fundamentales en las vidas de Pirie y Seeliger, investigadores de caracteres encontrados, teniendo como fondo la inmensa figura de Lister, del cual se presentan, más que sus hallazgos y realizaciones científicas, sus condiciones humanas: su ética inquebrantable, su desinterés por los honores, su profunda religiosidad, su amor por su esposa Agnes y sus dificultades para exponer sus ideas con fluidez.

\section{Referencias}

1.- Laín Entralgo P. Historia de la medicina. Salvat Editores S.A., Barcelona 1978; p. 486.

2.- Murray E G D, Webb R A, Swann M B R. A disease of rabbits characterized by large mononuclear leucocytosis, caused by a hitherto undescribed bacillus Bacterium monocytogenes (nova sp). J pathol Bacteriol 1926; 29: 407-39.

3.- Ledermann W. Brucella melitensis, una historia de amor. En: Una historia personal de las bacterias. RIL editores, Santiago 2007; 209-14.

4.- Swinney G N. William Speirs Bruce, Scotland, polar meteorology and oceanography. Museum of the World Ocean Congress. www.vitiaz.ru.

5.- Archives Hub. James Hunter Harvey Pirie collection. http:/www.archiveshub.ac.uk/ news/0301 pir.html
6.- Kurz B. Gerbil. En: Collier's Encyclopedia. Crowell Collier and Mac Millan, Inc, USA 1967; 10:730-1.

7.- Pirie J H H. A new disease of veld rodents: Tiger River disease. Pub S African Inst Med Res 1927; 3: 163-86.

8.- Barnechea M J. El Décimo Congreso Internacional de Medicina en Berlín. El Progreso Médico 1890; I: 112-6.

9.- Truax R. Lister, Joseph (First Baron Lister). En: Collier's Encyclopedia. Crowell Collier and Mac Millan, Inc, USA 1967; 14: 686-7.

10.- Young A. Escalpelo. Ediciones Garriga S.A. Madrid 1957; 165-92.

11.- Griffith F. The pneumococcus. Serological races of pneumococci. En: British Medical Council. A system of bacteriology in relation to medicine. His Majesty Stationery Office, London 1929; II: 201-5.

12.- Bentley R. Medical secondary metabolites play important roles in medicine: prospects for discovery of new drugs. Perspect Biol Med 1997; 40: 364-94.

13.- Burn CG. Clinical and pathological features of an infection caused by a new pathogen of the genus Listerella. Am J Pathol 1936; 12: 341-8.

14.- Benirschke K. Routes and types of infection in the fetus and newborn. Am J Dis Child 1960; 99: 714-21

15.- Delta B G, Scott R B, Booker Cr. Listeria meningitis in the newborn. Med Ann DC 1961; 30: 329-34

16.- Suárez Fernández G. Heinz P.R. Seeliger (1920-1997), eminente listeriólogo. Internatl Microbiol 1998; 1: 73-4.

17.- Paterson J S. The antigenic structure of organisms of the genus Listerella. J Pathol Bacteriol 1940; 51:427-36

18- García Krenich S. Remembrance :German soldier remembered for cherishing life. The Albuquerque Tribune; Thursday, February 8 2007. 